\title{
SEOM clinical guideline on hereditary colorectal cancer (2019)
}

\author{
C. Guillén-Ponce ${ }^{1} \mathbb{D} \cdot$ E. Lastra $^{2} \cdot$ I. Lorenzo-Lorenzo ${ }^{3} \cdot$ T. Martín Gómez $^{4} \cdot$ R. Morales Chamorro ${ }^{5}$. \\ A. B. Sánchez-Heras ${ }^{6}$ (D) R. Serrano ${ }^{7} \cdot$ M. C. Soriano Rodríguez ${ }^{8} \cdot$ J. L. Soto ${ }^{9} \cdot$ L. Robles $^{10}$
}

Received: 16 December 2019 / Accepted: 16 December 2019 / Published online: 24 January 2020

(c) The Author(s) 2020

\begin{abstract}
In the last 2 decades, clinical genetics on hereditary colorectal syndromes has shifted from just a molecular characterization of the different syndromes to the estimation of the individual risk of cancer and appropriate risk reduction strategies. In the last years, new specific therapies for some subgroups of patients have emerged as very effective alternatives. At the same time, germline multigene panel testing by next-generation sequencing (NGS) technology has become the new gold standard for molecular genetics.
\end{abstract}

Keywords Lynch syndrome $\cdot$ Adenomatous polyposis $\cdot$ Hereditary colorectal cancer $\cdot$ Colon cancer

\section{Introduction}

Identification of individuals and families with clinical criteria for early referral to a specialized genetic counseling unit (GCU) has been the basis for preventive medicine in familial-hereditary susceptibility to colorectal cancer so

C. Guillén-Ponce, E. L. Aras, I. Lorenzo-Lorenzo, T. M. Gómez, R. M. Chamorro, A. B. S. Heras, R. S. Blanch, M. del Carmen Soriano Rodríguez, J. L. Soto, L. Robles contributed equally to the preparation of the manuscript.

\section{Guillén-Ponce \\ carmen.guillen@salud.madrid.org \\ $\checkmark$ L. Robles \\ luis.robles@salud.madrid.org \\ E. Lastra \\ elastra@saludcastillayleon.es \\ I. Lorenzo-Lorenzo \\ isabel.lorenzo.lorenzo@sergas.es \\ T. Martín Gómez \\ teremg111@hotmail.com \\ R. Morales Chamorro \\ rmchamorro@sescam.jccm.es}

\section{A. B. Sánchez-Heras \\ sanchez_ana@gva.es \\ R. Serrano \\ rsblanch@hotmail.com}

M. C. Soriano Rodríguez mamsoro@hotmail.com

J. L. Soto soto_jos@gva.es far. Genetic counseling and risk reduction strategies have avoided many new cancer diagnoses and have helped these individuals understand and adapt to all the implications of genetic predisposition to colorectal cancer.

In the near future, somatic and germline multigene panel testing will be incorporated into the routine care of cancer, early from its diagnosis. Targeted therapies candidates will be identified through these predictive molecular profiles and

1 Medical Oncology Department, Hospital Universitario Ramón y Cajal, IRYCIS, Carretera de Colmenar Viejo, Km 9,100, 28034 Madrid, Spain

2 Medical Oncology Department, Hospital Universitario de Burgos, Burgos, Spain

3 Medical Oncology Department, Complejo Hospitalario Universitario de Vigo (CHUVI), Pontevedra, Spain

4 Medical Oncology Department, Hospital Universitario de Salamanca, Salamanca, Spain

5 Medical Oncology Department, Hospital General La Mancha Centro, Alcázar de San Juan, Ciudad Real, Spain

6 Medical Oncology Department, Hospital General Universitario de Elche, Elche, Alicante, Spain

7 Medical Oncology Department, Hospital Universitario Reina Sofía, IMIBIC, CIBERONC, Córdoba, Spain

8 Medical Oncology Department, Hospital General Virgen de la Luz, Cuenca, Spain

9 Molecular Genetics Laboratory, Hospital General Universitario de Elche, Elche, Alicante, Spain

10 Medical Oncology Department, Hospital Universitario Doce de Octubre, Madrid, Spain 
at the same time all known and actionable hereditary colorectal cancer syndromes will be screened as well.

The main hereditary colorectal cancer syndromes will be reviewed in this guideline with their main clinical, molecular features and their appropriate surveillance recommendations.

\section{Materials and methods}

A medical literature review was conducted in NCBI PubMed/EMBASE databases on the topics of the guideline. Evidence level and strength of the recommendations were based on GRADE http://www.gradeworkinggroup.org/ [1-3] (Table 1).

\section{Lynch syndrome (OMIM 120435)}

Lynch syndrome (LS) is an autosomal dominant inherited cancer predisposition disease. Its estimated general population prevalence is 1 in 279 [4]. LS accounts for about $3 \%$ of colorectal cancer (CRC) [5] and $2 \%$ of endometrial

Table 1 Evidence levels and strength of recommendation

Evidence levels
A: High. Randomized well-designed clinical trials/well-conducted
meta-analysis. It is unlikely that future studies on the topic will
modify confidence in the outcome
B: Moderate. Non-randomized prospective studies. It is likely
that future studies on the topic will modify the confidence in the
estimated outcome
C: Low or very low. Observational studies. Future studies on the
topic will very likely change not only the confidence in the out-
come but the outcome itself
Strength of recommendation
1. Strong recommendation on the measure/intervention we are
considering: advantages of the intervention outweigh the risks and
also are cost-efficient
2. Weak recommendation: advantages and disadvantages are not far
from each other

cancer (EC) cases [6]. CRC is the most common associated tumor, usually right-sided, poorly differentiated, with mucinous features or medullary growth pattern, abundant infiltrating lymphocytes, propensity for synchronous and/ or metachronic tumors [7], and a better prognosis in the non-metastatic setting $[8,9]$. LS also predisposes to EC, small intestinal, urinary tract, pancreaticobiliary, gastric and ovarian tumors, and slightly to breast and prostate cancers [7, 10-12]. Muir-Torre syndrome is characterized by skin tumors (sebaceous neoplasms, keratoacanthomas) and Turcot's syndrome includes glial brain tumors $[7,10]$. The age of onset is younger compared with sporadic counterparts: 45-60 years old (years) for CRC and 50 years for EC [13].

Lynch syndrome is caused by pathogenic germline variants in the DNA mismatch repair (MMR) genes $M L H 1$, $M S H 2, M S H 6$, or PMS2 (and in the non-MMR gene EpCAM, in which deletions induce epigenetic silencing of $\mathrm{MSH} 2$ ) $[10,14]$. When a second "hit" of somatic mutation occurs, the MMR function fails leading to cancers with microsatellite instability (MSI) and hypermutation phenotype. Deficient MMR (dMMR) and MSI are not exclusive to the LS and are also likely in sporadic cancers caused by $M L H 1$ promoter hypermethylation [15] or double somatic MMR mutations [16].

The age-specific cumulative risk could depend on genotype and sex [12, 13, 17-19] (Table 2). MSH2 mutation carriers have a higher risk of extracolonic cancers [12]. EpCAM deletions close to the $M S H 2$ promoter are associated with increased risk of EC [20]. MSH6 and PMS2 mutations have a lower penetrance [4], except for EC in MSH6 carriers, who also present with cancer at later ages [19, 21].

\section{LS diagnosis}

Universal strategy with molecular analyses in unselected CRC or EC adds diagnostic sensitivity for LS over clinical criteria, with a favorable cost-effectiveness profile [22-25]. This information has prognostic and therapeutic value for

Table 2 Lifetime cancer risks related to LS genotype and sex

\begin{tabular}{|c|c|c|c|c|c|c|c|c|}
\hline Cancer site & MLH1 male & MLH1 female & MSH2 male & MSH2 female & MSH6 male & MSH6 female & PMS2 male & PMS2 female \\
\hline Any LS cancer & $59 \%$ & $80 \%$ & $71 \%$ & $75 \%$ & $31 \%$ & $71 \%$ & & \\
\hline CRC & $34-47 \%$ & $36-45 \%$ & $37-47 \%$ & $33-37 \%$ & $14-22 \%$ & $10-26 \%$ & $13-20 \%$ & $11-15 \%$ \\
\hline $\mathrm{EC}$ & & $42.7 \%$ & & $56.7 \%$ & & $46.2 \%$ & & $13-24 \%$ \\
\hline Ovarian & & $10.1 \%$ & & $16.9 \%$ & & $13.1 \%$ & & \\
\hline Urinary tract & $1.2 \%$ & $3 \%$ & $8 \%$ & $10 \%$ & $0.7 \%$ & & & \\
\hline Gastric & $20 \%$ & $8 \%$ & $2 \%$ & $9 \%$ & & & & \\
\hline Small bowel & $0.4 \%$ & & $1.1 \%$ & & & & & \\
\hline Biliary/pancreatic & $1.9 \%$ & & $0.02 \%$ & & & & & \\
\hline CNS gliomas & $1.0 \%$ & & $5.3 \%$ & & $1.4 \%$ & & & \\
\hline
\end{tabular}

$C N S$ central nervous system, $C R C$ colorectal cancer, $E C$ endometrial cancer 
common clinical practice. Multigene NGS in CRC, including MMR and $B R A F$ genes, with computational tools for MSI testing, has a higher diagnostic sensitivity compared with a universal strategy based on immunohistochemistry (IHC) and BRAF analyses (100\% sensitivity [95\% CI 93.8-100] versus $89.7 \%$, [95\% CI 78.8-96.1], $p=0.04$ ) [26]. In a prospective study of $>15.000$ unselected cancer patients with 50 different histologies, a similar NGS device increased LS diagnostic sensitivity over revised Bethesda Criteria (rBC) plus universal strategy [27]. Somatic NGS panels are available in clinical practice for precision oncology due to their predictive value. Direct germline multigene NGS in unselected patients with CRC increases diagnostic sensitivity for less prevalent hereditary syndromes more than for LS [5, 28] (Fig. 1). When there are no tumor samples, fulfillment of $\mathrm{rBC}$ or $\mathrm{a} \geq 2.5 \%$ likelihood of LS on the validated PREMM $_{5}$ prediction model [29] can be used for referral to a GCU. Although NGS is continuously less expensive, cost-effectiveness studies for LS diagnostic strategies that incorporate these platforms are lacking.

Recommendation Different screening strategies for LS of all newly diagnosed CRC and EC can be considered including tumor tests for defective MMR function and/or highlevel MSI and/or NGS tumor sequencing including $B R A F$.

In case of lack of expression of MLH1 and PMS2 by immunohistochemistry, BRAFV600E mutation and/or $M L H 1$ promoter hypermethylation should be carried out to rule out sporadic cases.

Patients with molecular profiles compatible with LS should be referred to GCU for appropriate counseling and NGS germline genetic testing.

In families with fulfillment of $\mathrm{rBC}$ or $\mathrm{a} \geq 2.5 \%$ likelihood of LS on the $\mathrm{PREMM}_{5}$ prediction model, prevalent and/or previous CRC and/or EC should follow the same screening procedure before considering referral to GCU (evidence level B, strength 1).

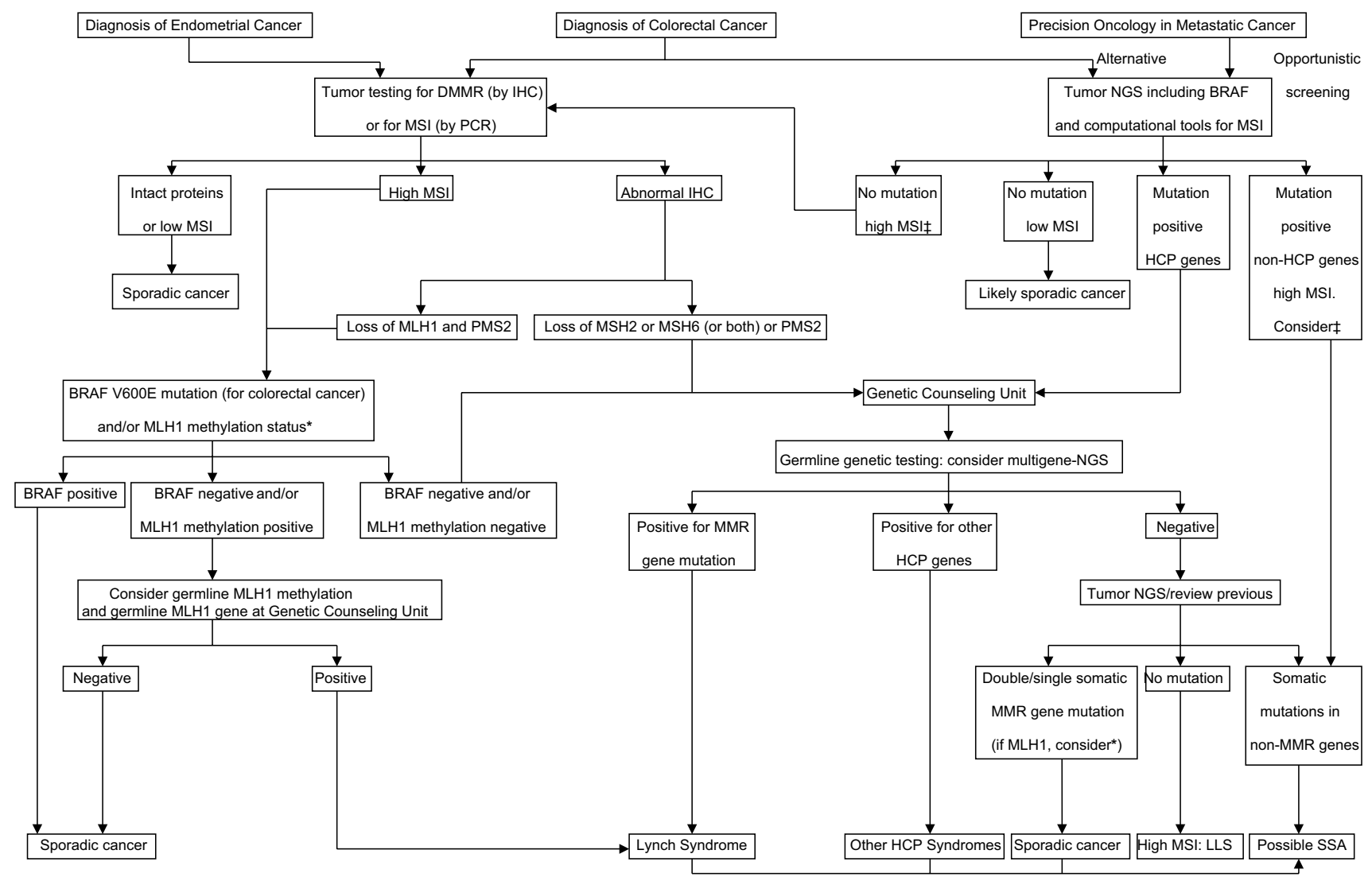

Fig. 1 Lynch Syndrome diagnostics. HCP hereditary cancer predisposition, LLS Lynch-like syndrome, MMR mismatch repair, MSI microsatellite instability, $N G S$ next-generation sequencing, SSA secondary somatic alterations 


\section{Management of LS: cancer prevention}

\section{Screening and surgical management for CRC prevention}

Prospective data with long-term follow-up demonstrate that early colonoscopy repeated frequently in LS carriers significantly reduces CRC incidence, CRC associated mortality, and overall mortality [30].

Recommendation Colonoscopies should be performed every $1-2$ years for healthy individuals with LS, beginning at 20-25 years or $2-5$ years before the youngest age at which CRC was diagnosed in the family if this occurred before 25 years (evidence level B, strength 1).

Risk of metachronous CRC is up to $62 \%$ at 30 -year follow-up among patients with LS and segmental resection of the primary tumor [31]. In a meta-analysis of 6 studies (mean 9-year follow-up), rates of metachronous CRC were reduced by 3.4 times with subtotal colectomy, although a survival benefit was not found [32].

Recommendation Extended colonic resection may be an option for young patients with CRC, severe LS phenotype, good bowel function, no comorbidities, and compliance with endoscopic surveillance after surgery (evidence level A, strength 1).

\section{Risk-reducing surgery for EC and ovarian cancer (OC)}

Observational data have shown that hysterectomy and salpingo-oophorectomy have efficacy for prevention of EC and OC in women with LS, although it remains unclear whether surgery confers any survival benefit [33]. Psychological, cardiovascular, endocrinologic, skeletal, and sexual consequences of early onset menopause, and the risk burden associated with specific genes must be kept in mind to discuss the optimal timing of risk-reducing surgery.

Recommendation Risk-reducing hysterectomy and salpingo-oophorectomy at the completion of childbearing and/ or since the early 40 s (evidence level C, strength 1 ) should be considered.

\section{Chemotherapeutic prevention}

A long-term analysis in CAPP2 study demonstrated a marked reduction in CRC incidence (incidence rate ratio [IRR], 0.37 [95\% CI 0.18-0.78], $p=0.008$ ) and in any LSassociated cancer (IRR, 0.42 [95\% CI 0.25-0.72], $p=0.001$ ) among LS carriers who took aspirin at dose of $600 \mathrm{mg} /$ day for 2 or more years compared with those randomly assigned to placebo [34].

Recommendation Daily aspirin can be considered for LS cancer prevention, although the ideal dose and duration of use are as yet undefined (evidence level A, strength 2).
Management of LS: specific issues on cancer treatment

Adjuvant chemotherapy with 5-fluorouracil did not result in a survival benefit in subgroup analyses of patients with stage II colon cancer with dMMR [35].

In patients with dMMR metastatic CRC and previous cytotoxic agents failure, anti-programmed death 1 (PD-1) antibody nivolumab resulted in objective response rate (ORR) of $31.1 \%$ (95\% CI 20.8-42.9) (median follow-up time, 12.0 months) [36]. In the same setting, the combination of nivolumab plus ipilimumab (anti-cytotoxic T-lymphocyte antigen 4 antibody) reached an ORR of 55\% (95\% CI 45.2-63.8) (median follow-up time, 13.4 months), with progression-free survival and overall survival rates at 12 months of $71 \%$ and $85 \%$, respectively, and a manageable treatment-related grade 3-4 toxicity in 32\% of patients [37]. In dMMR cancers across 12 different histologies, ORR of 53\% (95\% CI 42-64) and complete responses in $21 \%$ of patients (median follow-up time, 12.5 months) were observed with anti-PD-1 antibody pembrolizumab [38].

Recommendation Adjuvant chemotherapy is not indicated in stage II LS-associated colon cancer (evidence level B, strength 1). Different immunotherapy options are valid for pretreated recurrent or metastatic LS-associated cancers (evidence level B, strength 1).

\section{Familial adenomatous polyposis}

Familial adenomatous polyposis (FAP) was first associated with mutations in the $A P C$, and later in the $M U T Y H$. Additional genes such as POLE, POLD1, NTHL1, MSH3, GREM1 have been recently associated. Extracolonic manifestations may be present and help with the clinical diagnosis (Table 3).

\section{APC-associated polyposis, FAP or AAP (OMIM 175100) $[39,40]$}

It is an autosomal dominant inherited disease caused by germline mutations ( $>85 \%$ point mutations, $10-15 \%$ large rearrangements) in $A P C$ which encodes a protein with a significant role in the Wnt- $\beta$-catenin signaling. Up to $30 \%$ of carriers are due to de novo mutations or to somatic mosaicism. There are genotype-phenotype correlations. The clinical presentations are: (a) classic FAP, $\geq 100$ polyps, appearing between 10 and 30 years, first located in rectum and sigma afterwards along the colon and development of CRC in almost $100 \%$ if untreated, at a mean age of 39 years. (b) Attenuated FAP (AFAP), $<100$ polyps located in proximal colon and lesser risk of CRC, $70 \%$, at a mean age of 50-55 years. (c) Gastric adenocarcinoma and proximal polyposis of the stomach (GAPP), none or few polyps in colon. 


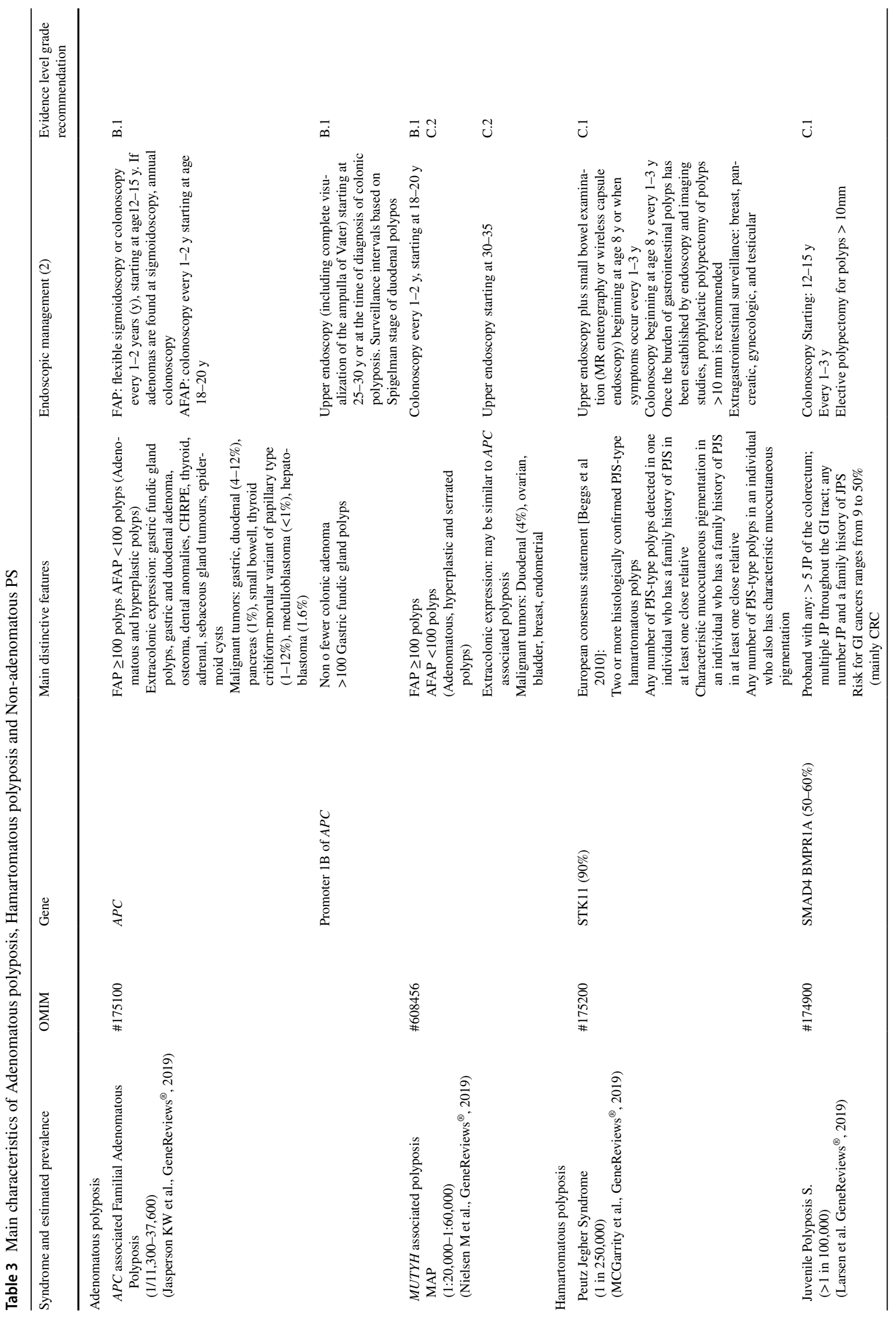




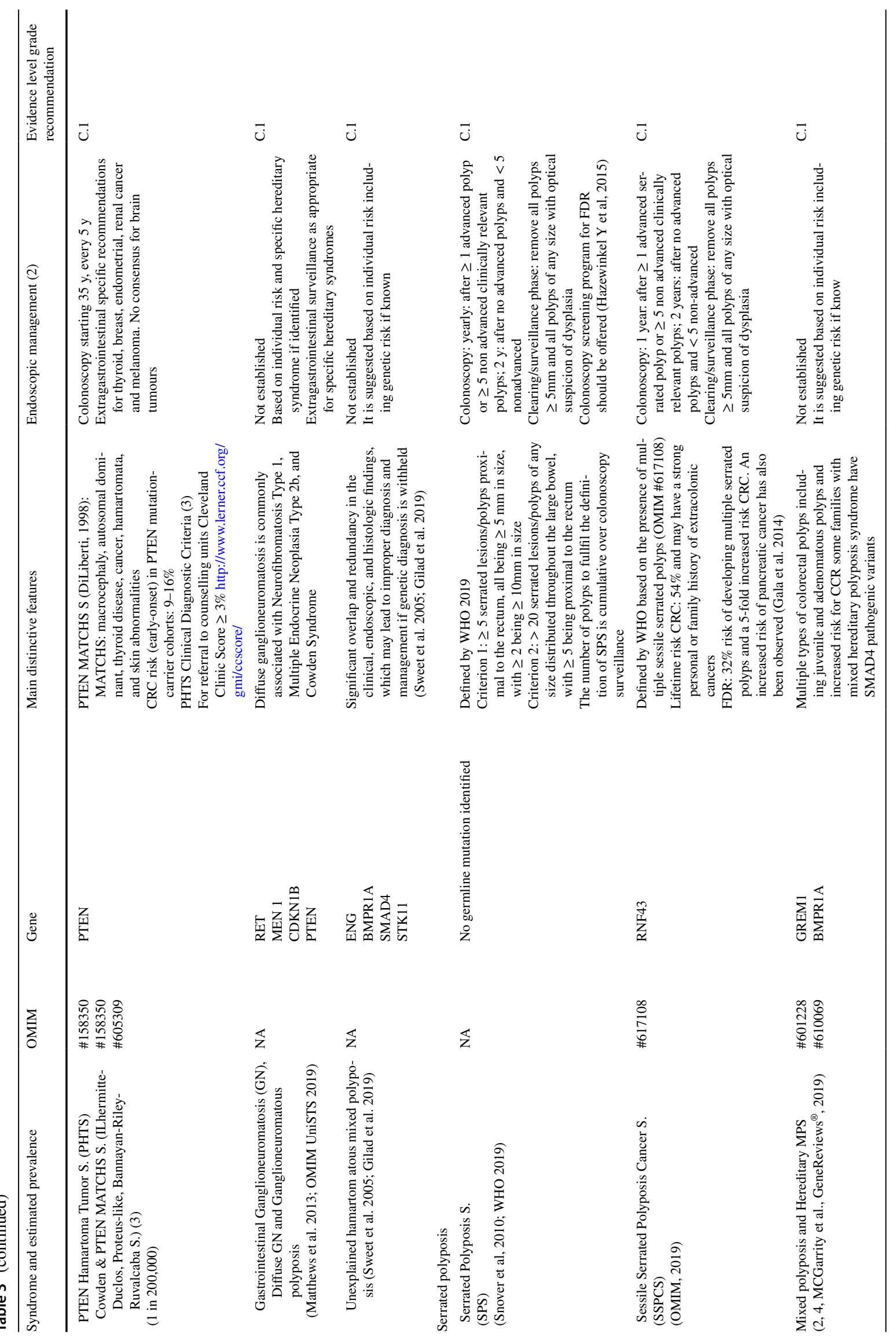




\section{MUTYH-associated polyposis, MAP (OMIM 608456)} $[39,41]$

It is an autosomal recessive disease caused by bi-allelic, homozygous or compound heterozygous, germline mutations ( $>99 \%$ point mutations, $<1 \%$ large rearrangement) in MUTYH which encodes a glycosylase of DNA base excision repair system. Somatic G:C to T:A transversions result in genes implicated in CRC carcinogenesis, such as $A P C$ or $K R A S$. The most frequent phenotype is AFAP, at a mean age of 45 years, but maybe classic FAP, serrated polyposis and few individuals develop CRC without polyposis. Genotype-phenotype correlation has been described. The risk of CRC is $43-100 \%$ at the age of 50 years.

For the study of FAP, single gene testing has been the traditional approach, but the use of a multigene panel should be specially considered in attenuated FAP.

Recommendation Criteria for referral to a GCU and APC/MUTYH or multigene panel testing (evidence level B, strength 1):

1. Patients with $>10$ synchronous adenomatous colonic polyps histologically confirmed.

2. Family history of adenomatous colonic polyps ( $>10$ in $>1$ relative), at young age and extracolonic manifestations.

3. Gastric polyps (>100), in body and fundus, preponderantly fundic glands polyps. Proton pump inhibitor use must be excluded.

4. Consider in: hepatoblastoma, desmoid tumor, cribriform-morular variant of papillary thyroid carcinoma, multifocal or bilateral congenital hypertrophy of retinal pigmented epithelium.

5. Known familial mutation in at-risk relatives.

\section{Colorectal surveillance}

In classical FAP, flexible sigmoidoscopy or colonoscopy should be carried out every 1-2 years, starting at age 12-15 years. If adenomas are found at sigmoidoscopy, then it should be annual colonoscopy [43]. In AFAP, colonoscopy should be performed every 1-2 years starting at age 18-20 years and surgery is indicated if there is a high number of adenomas. In MAP, colonoscopy should be performed every 1-2 years, starting at 18-20 years and if polyps cannot be controlled endoscopically, colectomy should be considered [43, 44]. For MUTYH heterozygote, colonoscopy should be performed every 5 years, beginning at age 40 years or 10 years prior to age of first-degree relative's age at CRC diagnosis [42, 44].

Recommendation Surgery is indicated if there is a high number of adenomas or a high degree of dysplasia (evidence level B, strength 1).

\section{Surgical options of colon and rectum}

Surgical options in FAP patients are total abdominal colectomy with ileorectal anastomosis (TAC/IRA) or total proctocolectomy with pouch anal anastomosis (TPC/IPAA) [42-44]. Surveillance of rectum depends on the type of surgery $[42,43]$.

Recommendation TPC/IPAA or TAC/IRA should be carried out depending on age, severity of rectal polyposis and risk of developing desmoids. In FAP, it is usually recommended in the 2 nd decade of life (evidence level $\mathrm{B}$, strength 1). IPAA is generally recommended for FAP, and IRA for AFAP and MAP. Afterwards, surveillance of the rectum should be carried out every 6-12 months if rectal tissue remains, and every 1-3 years if ileoanal pouch is present, depending on polyp burden (evidence level B, strength 1).

\section{Extracolonic manifestations}

For gastroduodenal adenomas, upper endoscopy (including complete visualization of the ampulla of Vater) should be performed starting at 25-30 years or at the time of diagnosis of colonic polyposis [43]. Surveillance intervals are based on the Spigelman's stage of duodenal polyposis: 0 (no polyposis): 4 years; I (1-4 tubular adenomas, 1-4 mm): 2-3 years; II (5-19 tubular adenomas, 5-9 $\mathrm{mm}$ ): 1-3 years; III ( $\geq 20, \geq 1 \mathrm{~cm}$ ): 6-12 months; and IV (dense polyposis or high grade): surgery [42, 44]. Duodenal adenomas are managed by endoscopic polypectomy, although duodenectomy or duodenal pancreatectomy may be necessary in advanced cases [43].

Patients with classical FAP have a lifetime thyroid cancer risk of 2-6\% and annual surveillance is recommended [42, 44].

Treatments for desmoid tumors are surgery, non-steroid anti-inflammatory drugs (NSAIDs), anti-oestrogen agents, chemotherapy, imatinib, sorafenib, pazopanib and radiotherapy [44].

The absolute risk for hepatoblastoma in FAP is estimated at less than $2 \%$ and it occurs prior to the age of 3 years [42].

Recommendation Surveillance of duodenal adenomas is based on the Spigelman's stage (evidence level B, strength 1). In MAP, upper endoscopy is recommended at 30-35 years (evidence level C, grade 2). For thyroid cancer, annual thyroid examination and thyroid ultrasound should start at 25-30 years (evidence level C, strength 2). For desmoid tumors, annual abdominal palpation and magnetic resonancy (MRI) or computer tomography (CT) scan should be done within 1-3 years post-colectomy and then every 5-10 years (evidence level C, strength 2); also surgery should be reserved for small, well-defined tumors, and if a 
Table 4 Refering to clinical genetics for CRC

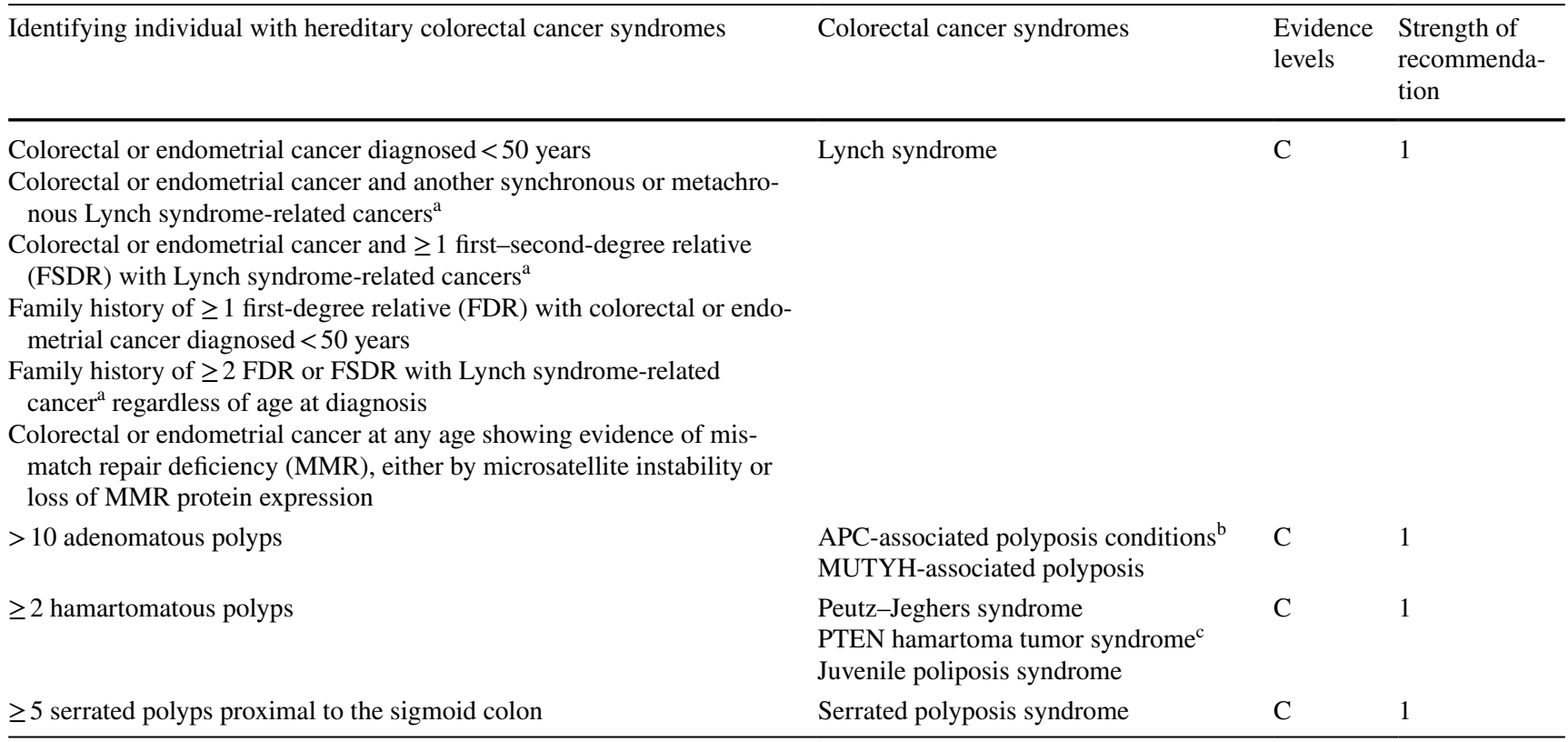

a'Lynch syndrome-related cancers: colorectal, endometrial, gastric, ovarian, pancreatic, ureter and renal pelvis, brain, small intestinal cancer and sebaceous adenoma, sebaceous carcinoma, keratoacanthoma

${ }^{\mathrm{b}} \mathrm{APC}$-associated polyposis conditions: familial adenomatous polyposis, attenuated familial adenomatous polyposis

${ }^{c}$ PTEN hamartoma tumor syndrome: Cowden syndrome, Bannayan-Riley-Ruvalcaba syndrome, PTEN-related proteus syndrome, proteus-like syndrome

clear margin can be obtained (evidence level B, strength 2). For hepatoblastoma, consider liver palpation, abdominal ultrasound and alpha-fetoprotein (AFP) measurement every 3-6 months before 5 years (evidence level C, strength 2).

\section{Chemoprevention}

The use of NSAIDs (sulindac or celecoxib) has been shown to reduce the number and extent of CRC and duodenal adenomas, but without the clinical benefit of decrease in cancer risk $[42,43]$. Due to the cardiovascular risk of NSAIDs, no drug has been approved.

Recommendation The use of NSAIDs to prevent CRC and duodenal adenomas needs to be balanced with the side effects (evidence level A, strength 2).

\section{Hamartomatous polyposis and other non-adenomatous polyposis}

There are several classifications for hereditary syndromes with polyposis; one of the most accepted distributes them into four large groups: adenomatous, hamartomatous, serrated and mixed polyposis [45].

These PS are very rare with the exception of serrated polyposis syndrome (SPS); the estimated incidence for PTEN hamartoma tumor syndrome is 1 in 200,000-250,000; for
Peutz-Jeghers syndrome it is 1 in 250,000; for juvenile polyposis syndrome it is from 1 to 1.6 in 100,000. The SPS prevalence is higher than for other PS, including FAP; overall, its seems lower than 0.09-42 in 10,000 in colonoscopy-based CRC screening programs, but it is considerably higher in positive fecal occult blood test populations, with estimates of $0.34-0.66 \%$ or $31-80$ in 10,000 [46-51]. Sessile serrated polyposis cancer syndrome (SSPCS) is a very rare disorder caused by heterozygous mutation in the RNF43 gene [49]. While most SPS cases are sporadic, evidence suggests that this syndrome exhibits a genetic component at least occasionally. The higher prevalence of CRC and serrated polyps in first-degree relatives (FDRs) as compared to the general population supports this theory.

Table 3 summarizes the main characteristics and recommendations of surveillance of Adenomatous polyposis, Hamartomatous polyposis and Non-adenomatous PS according to recommendations of the European Society of Gastrointestinal Endoscopy (ESGE) Guideline [46] or, in the rest of the cases, suggested by other referenced authors.

\section{Multigene panel testing in familial CRC}

The introduction of NGS technologies for the genetic diagnosis of hereditary cancer predisposition syndromes represents a surpassing progress in the knowledge of this field. Multigene panel testing allows the simultaneous analysis 


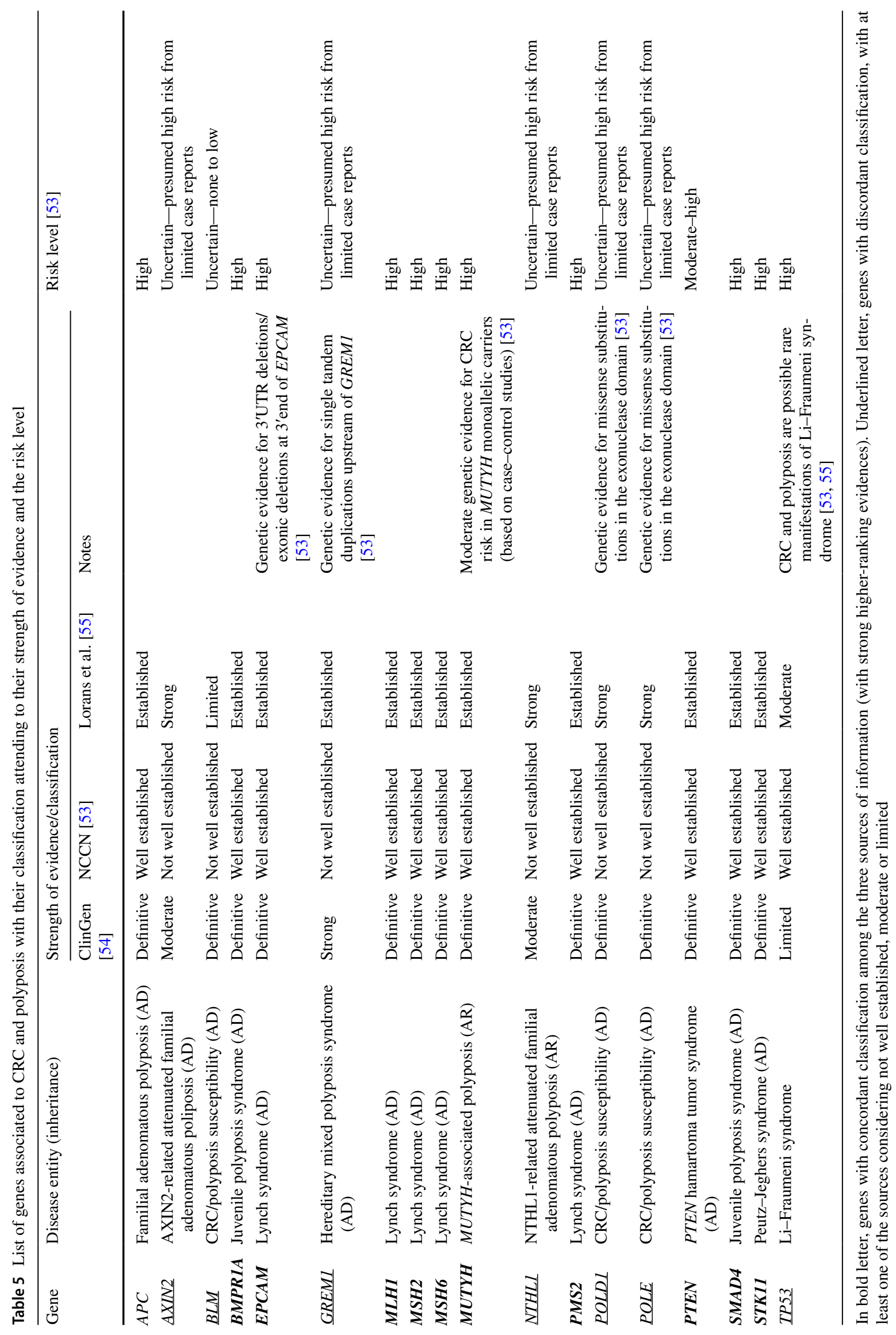


of multiple genes by NGS increasing the diagnostic yield, reducing the response times in a cost-effective manner, when compared to iterative single gene or phenotype-driven testing [52]. On the other hand, there is a higher chance of identifying variants of uncertain significance that are not actionable, or variants for which clinical management is uncertain such as finding a pathogenic variant in a moderate risk gene [53].

There is a high variability in the genes included across the multigene panels for CRC. Although a batch of genes considered clinically actionable with quantified magnitude of risk are present in virtually all panels, there is a significant amount of genes that lack comprehensive validation or have less evidence of association with CRC/polyposis and consequently minimal clinical utility, that are included in many multigene panels. In fact, recent data from the ClinGen Clinical Validity framework show that $<60 \%$ of the genes on clinically available panels have strong or definitive evidence of association with hereditary colorectal cancer or polyposis, and $>40 \%$ have only moderate, limited, disputed, or refuted evidence [54].

The current lack of consensus regarding inclusion of genes in CRC panels represents a challenge in patient counseling and management (Table 4). There is an urgent need to provide consensus on the genes included in multigene panels. This consensus should be based on structured assessment of the clinical relevance of the genes, with standardized reporting and clinical management guidelines [55].

For the current guidelines, we have reviewed the available information from reputable sources with expert panels to define strength of evidence and evaluate the clinical utility of genes associated with $\mathrm{CRC}$ and polyposis. Therefore, we considered the following sources: (i) the NCCN Guidelines for colorectal cancer v1.2019 [53], (ii) ClinGen Clinical Validity framework [54] and (iii) Lorans et al.'s review [55]. The applied criteria to evaluate the level of validation are slightly different among them with some discordant results. In Table 5, the list of genes considered to have strong higherranking evidences for their association to hereditary forms of CRC/polyposis in at least one of the considered sources is shown. The total number of included genes is 18 . Eleven genes have fully concordant classification among the three sources: APC, BMPRIA, EPCAM, MLH1, MSH2, MSH6, MUTYH, PMS2, PTEN, SMAD4 and STK11, while seven genes show discordant classification: AXIN2, BLM, GREM1, NTHL1, POLD1, POLE and TP53. Multigene panel testing for hereditary CRC and polyposis is a rapidly evolving landscape. A periodical review and consequent actualization of panels, if necessary, is recommended.

Recommendation Multigene panel testing for hereditary $\mathrm{CRC}$ and polyposis should include the genes:
- APC, BMPRIA, EPCAM, MLH1, MSH2, MSH6, MUTYH, PMS2, PTEN, SMAD4 and STK11 (evidence level A, strength 1).

- AXIN2, BLM, GREM1, NTHL1, POLD1, POLE and TP53 (evidence level B, strength 2).

\section{Compliance with ethical standards}

Conflict of interest CGP reports congress registration and accommodation from Sanofi. ELA has nothing to disclose. ILL has nothing to disclose. TMG reports congress registration and accommodation from Roche. RMCH reports consultant or advisory role from Servier, Celgene, Sanofi, Innoup Farma; speaker for Sanofi, Rovi, HoffmannRoche, Servier, Nutricia Oncology, Bristol-Myers Squibb, AstraZeneca, Pfizer, Takeda, Ipsen Pharma, Merck Sharp and Dohme, Bayer Hispania and PharmaMar; Travel and Accommodation from Eli Lilly and Company and Kyowa Kirin. ABSH reports a consultant or advisory role from Tesaro; honoraria for being a speaker for Roche and AstraZeneca and travel and congress assistance from MSD. RSB has nothing to disclose. CSR has nothing to disclose. JLS has nothing to disclose. LR reports congress registration from Roche and Servier and honoraria for being a speaker for Astrazeneca.

Ethical standards This guideline has been performed in accordance with the ethical standards laid down in the 1964 Declaration of Helsinki and its later amendments.

Informed consent There is not an informed consent statement for the elaboration of this guideline.

Open Access This article is licensed under a Creative Commons Attribution 4.0 International License, which permits use, sharing, adaptation, distribution and reproduction in any medium or format, as long as you give appropriate credit to the original author(s) and the source, provide a link to the Creative Commons licence, and indicate if changes were made. The images or other third party material in this article are included in the article's Creative Commons licence, unless indicated otherwise in a credit line to the material. If material is not included in the article's Creative Commons licence and your intended use is not permitted by statutory regulation or exceeds the permitted use, you will need to obtain permission directly from the copyright holder. To view a copy of this licence, visit http://creativecommons.org/licenses/by/4.0/.

\section{References}

1. Guyatt GH, Oxman AD, Vist GE, Kunz R, Falck-Ytter Y, Alonso-Coello P, et al. GRADE: an emerging consensus on rating quality of evidence and strength of recommendations. BMJ. 2008;336(7650):924-6.

2. Guyatt GH, Oxman AD, Kunz R, Vist GE, Falck-Ytter Y, Schünemann HJ. What is "quality of evidence" and why is it important to clinicians? BMJ. 2008;336(7651):995-8.

3. Guyatt GH, Oxman AD, Kunz R, Falck-Ytter Y, Vist GE, Liberati A, et al. Going from evidence to recommendations. BMJ. 2008;336(7652):1049-51.

4. Win AK, Jenkins MA, Dowty JG, Antoniou AC, Lee A, Giles $\mathrm{GG}$, et al. Prevalence and penetrance of major genes and 
polygenes for colorectal cancer. Cancer Epidemiol Biomark Prev. 2017;26(3):404-12.

5. Yurgelun MB, Kulke MH, Fuchs CS, Allen BA, Uno H, Hornick JL, et al. Cancer susceptibility gene mutations in individuals with colorectal cancer. J Clin Oncol. 2017;35(10):1086-95.

6. Watkins JC, Yang EJ, Muto MG, Feltmate CM, Berkowitz RS, Horowitz NS, et al. Universal screening for mismatch-repair deficiency in endometrial cancers to identify patients with Lynch syndrome and Lynch-like Syndrome. Int J Gynecol Pathol. 2017;36(2):115-27.

7. Lynch HT, Snyder CL, Shaw TG, Heinen CD, Hitchins MP. Milestones of Lynch syndrome: 1895-2015. Nat Rev Cancer. 2015;15(3):181-94.

8. Popat S, Houlston RS. A systematic review and meta-analysis of the relationship between chromosome 18q genotype, DCC status and colorectal cancer prognosis. Eur J Cancer. 2005;41(14):2060-70.

9. Zaanan A, Shi Q, Taieb J, Alberts SR, Meyers JP, Smyrk TC, et al. Role of deficient DNA mismatch repair status in patients with stage III colon cancer treated with FOLFOX adjuvant chemotherapy: a pooled analysis from 2 randomized clinical trials. JAMA Oncol. 2018;4(3):379-83.

10. Syngal S, Brand RE, Church JM, Giardiello FM, Hampel HL, Burt RW. AGC clinical guideline: genetic testing and management of hereditary gastrointestinal cancer syndromes. Am J Gastroenterol. 2015;110(2):223-63.

11. Watson P, Vasen HFA, Mecklin JP, Bernstein I, Aarnio M, Järvinen HJ, et al. The risk of extra-colonic, extra-endometrial cancer in the Lynch syndrome. Int J Cancer. 2008;123(2):444-9.

12. Møller P, Seppälä TT, Bernstein I, Holinski-Feder E, Sala P, Evans DG, et al. Cancer risk and survival in path_MMR carriers by gene and gender up to 75 years of age: a report from the Prospective Lynch Syndrome Database. Gut. 2018;67(7):1306-16.

13. Møller P, Seppälä T, Bernstein I, Holinski-Feder E, Sala P, Evans DG, et al. Cancer incidence and survival in Lynch syndrome patients receiving colonoscopic and gynaecological surveillance: first report from the prospective Lynch syndrome database. Gut. 2017;66(3):464-72.

14. Boland CR, Lynch HT. The history of Lynch syndrome. Fam Cancer. 2013;12(2):145-57.

15. Poynter JN, Siegmund KD, Weisenberger DJ, Long TI, Thibodeau SN, Lindor N, et al. Molecular characterization of MSI-H colorectal cancer by MLHI promoter methylation, immunohistochemistry, and mismatch repair germline mutation screening. Cancer Epidemiol Biomark Prev. 2008;17(11):3208-15.

16. Haraldsdottir S, Hampel H, Tomsic J, Frankel WL, Pearlman $\mathrm{R}$, de la Chapelle A, et al. Colon and endometrial cancers with mismatch repair deficiency can arise from somatic, rather than germline, mutations. Gastroenterology. 2014;147(6):1308-16.

17. Ten Broeke SW, van der Klift HM, Tops CMJ, Aretz S, Bernstein I, Buchanan DD, et al. Cancer risks for PMS2-associated Lynch syndrome. J Clin Oncol. 2018;36(29):2961-8.

18. Win AK, Lindor NM. Lynch syndrome (hereditary nonpolyposis colorectal cancer): clinical manifestations and diagnosis. Uptodate.com. 2019.

19. Bonadona V, Bonaiti B, Olschwang S, Grandjouan S, Huiart L, Longy $\mathrm{M}$, et al. Cancer risks associated with germ-line mutations in MLH1, MSH2, and MSH6 genes in Lynch syndrome. JAMA. 2011;305(22):2304-10.

20. Kempers MJ, Kuiper RP, Ockeloen CW, Chappuis PO, Hutter $\mathrm{P}$, Rahner N, et al. Risk of colorectal and endometrial cancers in EPCAM deletion-positive Lynch syndrome: a cohort study. Lancet Oncol. 2011;12(1):49-55.

21. Baglietto L, Lindor NM, Dowty JG, White DM, Wagner A, Gómez García EB, et al. Risks of Lynch syndrome cancers for MSH6 mutation carriers. J Natl Cancer Inst. 2010;102(3):193-201.

22. Moreira L, Balaguer F, Lindor N, de la Chapelle A, Hampel H, Aaltonen LA, et al. Identification of Lynch syndrome among patients with colorectal cancer. JAMA. 2012;308(15):1555-65.

23. Leenen $\mathrm{CH}$, Goverde A, de Bekker-Grob EW, Wagner A, van Lier MG, Spaander MC, et al. Cost-effectiveness of routine screening for Lynch syndrome in colorectal cancer patients up to 70 years of age. Genet Med. 2016;18(10):966-73.

24. Buchanan DD, Tan YY, Walsh MD, Clendenning M, Metcalf AM, Ferguson K, et al. Tumor mismatch repair immunohistochemistry and DNA MLH1 methylation testing of patients with endometrial cancer diagnosed at age younger than 60 years optimizes triage for population-level germline mismatch repair gene mutation testing. J Clin Oncol. 2014;32(2):90-100.

25. Goverde A, Spaander MC, van Doorn HC, Dubbink HJ, van den Ouweland AM, Tops CM, et al. Cost-effectiveness of routine screening for Lynch syndrome in endometrial cancer patients up to 70 years of age. Gynecol Oncol. 2016;143(3):453-9.

26. Hampel H, Pearlman R, Beightol M, Zhao W, Jones D, Frankel $\mathrm{WL}$, et al. Assessment of tumor sequencing as a replacement for Lynch syndrome screening and current molecular tests for patients with colorectal cancer. JAMA Oncol. 2018;4(6):806-13.

27. Latham A, Srinivasan P, Kemel Y, Shia J, Bandlamudi C, Mandelker D, et al. Microsatellite instability is associated with the presence of Lynch syndrome pan-cancer. J Clin Oncol. 2019;37(4):286-95.

28. Pearlman R, Frankel WL, Swanson B, Zhao W, Yilmaz A, Miller $\mathrm{K}$, et al. Prevalence and spectrum of germline cancer susceptibility gene mutations among patients with early-onset colorectal cancer. JAMA Oncol. 2017;3(4):464-71.

29. Kastrinos F, Uno H, Ukaegbu C, Alvero C, McFarland A, Yurgelun MB, et al. Development and validation of the PREMM $_{5}$ model for comprehensive risk assessment of Lynch syndrome. J Clin Oncol. 2017;35(19):2165-72.

30. Jarvinen HJ, Aarnio M, Mustonen H, Aktan-Collan K, Aaltonen LA, Peltomäki $\mathrm{P}$, et al. Controlled 15-year trial on screening for colorectal cancer in families with hereditary nonpolyposis colorectal cancer. Gastroenterology. 2000;118(5):829-34.

31. Parry S, Win AK, Parry B, Macrae FA, Gurrin LC, Church JM, et al. Metachronous colorectal cancer risk for mismatch repair gene mutation carriers: the advantage of more extensive colon surgery. Gut. 2011;60(7):950-7.

32. Heneghan HM, Martin ST, Winter DC. Segmental vs extended colectomy in the management of hereditary nonpolyposis colorectal cancer: a systematic review and meta-analysis. Colorectal Dis. 2015;17(5):382-9.

33. Schmeler KM, Lynch HT, Chen LM, Munsell MF, Soliman PT, Clark MB, et al. Prophylactic surgery to reduce the risk of gynecologic cancers in the Lynch syndrome. N Engl J Med. 2006;354(3):261-9.

34. Burn J, Gerdes AM, Macrae F, Mecklin JP, Moeslein G, Olschwang S, et al. Long-term effect of aspirin on cancer risk in carriers of hereditary colorectal cancer: an analysis from the CAPP2 randomised controlled trial. Lancet. 2011;378(9809):2081-7.

35. Sargent DJ, Marsoni S, Monges G, Thibodeau SN, Labianca R, Hamilton SR, et al. Defective mismatch repair as a predictive marker for lack of efficacy of fluorouracil based adjuvant therapy in colon cancer. J Clin Oncol. 2010;28(20):3219-26.

36. Overman MJ, McDermott R, Leach JL, Lonardi S, Lenz HJ, Morse MA, et al. Nivolumab in patients with metastatic DNA mismatch repair-deficient or microsatellite instability-high colorectal cancer (CheckMate 142): an open-label, multicentre, phase 2 study. Lancet Oncol. 2017;18(9):1182-91.

37. Overman MJ, Lonardi S, Wong KYM, Lenz HJ, Gelsomino F, Aglietta M. Durable clinical benefit with nivolumab plus 
ipilimumab in DNA mismatch repair-deficient/microsatellite instability high metastatic colorectal cancer. J Clin Oncol. 2018;36(8):773-9.

38. Le DT, Durham JN, Smith KN, Wang H, Bartlett BR, Aulakh LK, et al. Mismatch repair deficiency predicts response of solid tumors to PD-1 blockade. Science. 2017;357(6349):409-13.

39. Valle L. Recent discoveries in the genetics of familial colorectal cancer and polyposis. Clin Gastroenterol Hepatol. 2017;15:809-19.

40. Nielsen M, Aretz S. Familial adenomatous polyposis or APCassociated polyposis. In: Valle L, Gruber SB, Capellá G, editors. Hereditary colorectal cancer. Genetic basis and clinical implications. Cham: Springer International Publishing AG; 2018. p. 99-112.

41. Nielsen M, Aretz S. Adenomatous polyposis syndromes: MUTYH-associated polyposis. In: Valle L, Gruber SB, Capellá G, editors. Hereditary colorectal cancer. Genetic basis and clinical implications. Cham: Springer International Publishing AG; 2018. p. $135-48$.

42. Genetic/Familial High-Risk Assessment: Colorectal. NCCN Clinical Practice Guidelines in Oncology. Version 2.2019. 2019. https ://www.nccn.org/professionals/physician_gls/pdf/genetics_colon .pdf.

43. Stjepanovic N, Moreira L, Carneiro F, Balaguer F, Cervantes A, Balmaña J, et al. Hereditary gastrointestinal cancers: ESMO Clinical Practice Guidelines for diagnosis, treatment and follow-up. Ann Oncol. 2019;30:1558-71.

44. Herzig D, Hardiman K, Weiser M, You N, Paquette I, Feingold DL, et al. The American Society of Colon and Rectal Surgeons clinical practice guidelines for the management of inherited polyposis syndromes. Dis Colon Rectum. 2017;60(9):881-94.

45. Urioste Azcorra M. Aspectos moleculares de los síndromes polipósicos. In: Cáncer hereditario. $3^{\mathrm{a}}$ Ed. (C) 2019. Sociedad Española de Oncología Médica (SEOM). ISBN: 978-84-09-10462-8.

46. van Leerdam ME, Roos VH, van Hooft JE, Dekker E, Jover R, Kaminski MF, et al. Endoscopic management of polyposis syndromes: European Society of Gastrointestinal Endoscopy (ESGE) guideline. Endoscopy. 2019;51(9):877-95.

47. Larsen Haidle J, Howe JR. Juvenile polyposis syndrome. 2003 May 13 [Updated 2017 Mar 9]. In: Adam MP, Ardinger HH,
Pagon RA, et al., editors. GeneReviews ${ }^{\circledR}$ [Internet]. Seattle: University of Washington, Seattle; 1993-2019. https://www.ncbi.nlm. nih.gov/books/.

48. McGarrity TJ, Amos CI, Baker MJ. Peutz-Jeghers syndrome. 2001 Feb 23 [Updated 2016 Jul 14]. In: Adam MP, Ardinger HH, Pagon RA, et al., editors. GeneReviews ${ }^{\circledR}$ [Internet]. Seattle: University of Washington, Seattle; 1993-2019. https://www.ncbi.nlm.nih.gov/ books/.

49. Pilarski R. PTEN Hamartoma tumor syndrome: a clinical overview. Cancers. 2019;11(6):844.

50. OMIM: \# 617108. Sessile serrated polyposis cancer syndrome; SSPCS. https://www.omim.org/entry/617108? search $=\% 23617$ 108\&highlight=617108. Accessed 21 Aug 2019.

51. Stanich PP, Pearlman R, Hinton A, Gutierrez S, LaDuca H, Hampel H, Jasperson K. Prevalence of germline mutations in polyposis and colorectal cancer-associated genes in patients with multiple colorectal polyps. Clin Gastroenterol Hepatol. 2019;17(10):2008-15.

52. Gallego CJ, Shirts BH, Bennette CS, Guzauskas G, Amendola LM, Horike-Pyne M, et al. Next-generation sequencing panels for the diagnosis of colorectal cancer and polyposis syndromes: a cost-effectiveness analysis. J Clin Oncol. 2015;33(18):2084-91.

53. Provenzale D, Gupta S, Ahnen DJ, Chen L-M, Chung DC, Cooper $\mathrm{G}$, et al. NCCN guidelines. genetic/familial high risk assessment: colorectal v1.3019. 2019.

54. Seifert BA, McGlaughon JL, Jackson SA, Ritter DI, Roberts ME, Schmidt RJ, et al. Determining the clinical validity of hereditary colorectal cancer and polyposis susceptibility genes using the Clinical Genome Resource Clinical Validity Framework. Genet Med. 2019;21(7):1507-16.

55. Lorans M, Dow E, Macrae FA, Winship IM, Buchanan DD. Update on hereditary colorectal cancer: improving the clinical utility of multigene panel testing. Clin Colorectal Cancer. 2018;17(2):e293-305.

Publisher's Note Springer Nature remains neutral with regard to jurisdictional claims in published maps and institutional affiliations. 